cognitive developmental outcome than indomethacin, but this may be an effect of using both the Bayley-II as the Bayley-III.

\section{INTRAUTERINE GROWTH RESTRICTION AND VERY PRETERM BIRTH ARE ASSOCIATED WITH MOTOR DYSFUNCTION AND WHITE MATTER PATHOLOGY AT SCHOOL AGE}

doi:10.1136/archdischild-2012-302724.1266

${ }^{1} \mathrm{E}$ Morsing, ${ }^{2} \mathrm{~A}$ Kahn, ${ }^{1} \mathrm{D}$ Ley, $21 \mathrm{Björkman-Burtscher,}{ }^{3} \mathrm{~K}$ Marsal. 'Department of Pediatrics; 'Department of Radiology; ${ }^{3}$ Department of Obstetrics and Gynecology, Clinical Sciences Lund, Lund University, Lund, Sweden

Objective To assess neuromotor ability and white matter (WM) pathology at early school age in children delivered at very early gestation due to intrauterine growth restriction (IUGR) with abnormal fetal blood flow.

Design Morphological 3T MRI and Movement assessment battery for children $(\mathrm{ABC})$ were performed at median 8.5 years of age (range 7-11) in 27 children with IUGR and abnormal fetal blood flow born at a median of 26.9 (range 24-29) gestational weeks (PT-IUGR) to assess WM morphology and motor skills. Control groups were matched for gender and age and had birthweight appropriate for gestational age (AGA); 26 preterm (PT-AGA), born at 26.9 (range 24-29) gestational weeks and 28 term children (T-AGA).

Results Children with cerebral palsy in the PT-IUGR $(n=3)$ and PT-AGA group $(n=4)$ were excluded from further analysis. The PTIUGR group had significantly higher rate of WM pathology compared to the T-AGA group ( $\mathrm{p}<0.001)$ whereas PT-AGA did not differ from the other groups. WM pathology was found in $39 \%, 14 \%$ and $0 \%$ in the PT-IUGR, PT-AGA and T-AGA groups respectively.

Higher scores on $A B C$, reflecting impaired motor skills, were found in the PT-IUGR mean (SD) 9.7 (5.5) compared to the PT-AGA 5.3 (4.1) and T-AGA 3.9 (3.7) children ( $\mathrm{p}=0.004$ and $<0.001$, respectively). WM pathology found on MRI was not related to ABCmovement scores.

Conclusion IUGR with abnormal fetal blood flow in infants born very preterm has an additional negative impact on motor outcome and WM morphology at early school age.

\section{ANTENATAL CORTICOSTEROIDS AND PULMONARY HYPERTENSION TREATED WITH INHALED NITRIC OXIDE ARE ASSOCIATED WITH NEURODEVELOPMENTAL OUTCOMES OF ELBW INFANTS}

doi:10.1136/archdischild-2012-302724.1267

'M Nishihara, 'J Shiraishi, 'S Hirano, 'E Yamamoto, 'H Kitajima. 'Department of Neonatology; ' ${ }^{2}$ Department of Child Psychiatry, Osaka Medical Center and Research Institute for Maternal and Child Health, Izumi, Japan

Background and Aims To describe neurodevelopmental outcomes of ELBW infants in our NICU and to identify characteristics associated with severe disability.

Methods A retrospective cohort study was conducted to collect perinatal factors and neurodevelopmental outcomes at 3 years old among extremely low birth weight (ELBW) infants admitted to the level III NICU at Osaka Medical Center and Research Institute for Maternal and Child Health in Japan from January 1, 2003 to December 31, 2007. Logistic regression was used to identify characteristics associated with cerebral palsy (CP) and mental retardation (MR: corrected developmental quotient $<70$ ).

Results 201 ELBW infants without major congenital anomalies were admitted and 28 (13.9\%) of them were discharged by death. Of the remaining 173 survivors, 153 (88.4\%) were evaluated. CP and MR occurred in 37 (24.2\%) of the assessed infants. Multivariate logistic regression suggested antenatal corticosteroids $(45.9 \%$ vs
$71.6 \%$; adjusted odds ratio, 0.29 [95\% CI, 0.14-0.68]) and pulmonary hypertension $(\mathrm{PH})$ treated with inhaled nitric oxide (iNO) $(8.1 \%$ vs $0.9 \%$; adjusted odds ratio, 13.19 [95\% CI, 1.23-138.34]) were the characteristics most highly associated with CP and MR. Of 3 infants, who had suffered from $\mathrm{PH}$ treated with iNO at birth and subsequently had CP and MR, 2 infants were delivered after premature rupture of the membranes and 1 was delivered at home accidentally.

Conclusions Antenatal corticosteroids and $\mathrm{PH}$ treated with iNO are associated with severe disability of ELBW infants. Further prospective studies involving large samples are required to confirm these results.

\section{USE OF HEALTH CARE RESOURCES BY SURVIVING VERY LOW BIRTH WEIGHT (VLBW) INFANTS AFTER DISCHARGE TO HOME}

doi:10.1136/archdischild-2012-302724.1268

${ }^{1.2}{ }^{2} \mathrm{D}$ Bratlid, ${ }^{2} \mathrm{KE}$ Heltne. ${ }^{1}$ Pediatrics and Adolescent Medicine, St. Olavs University Hospital; 'Institute of Laboratory Medicine, Children's and Women's Health, Faculty of Medicine, Norwegian University for Science and Technology, Trondheim, Norway

Background and Aims VLBW infants require intensive care in the neonatal period and to discharge. The aim of this investigation was to study the extent to which surviving children with birth weight $(\mathrm{BW})<1500 \mathrm{~g}$ was in need of medical specialist healthcare services as well as drug treatment after discharge to home.

Methods The study was conducted as a retrospective cohort study where four cohorts (1997, 1998, 2004, and 2007) of VLBW infants were followed. Data on perinatal factors that could contribute to increased risk for future health care needs, hospital admissions and outpatient visits as well as drug prescriptions after discharge were obtained from patient records. The study included 152 infants.

Results The study shows that VLBW infants have a significant need for later health care resources, particularly the first 4-7 years after discharge. During the first 4 years $70 \%$ of infants had been hospitalized with $3.6 \pm 6.0$ admissions. They spent $25 \pm 29$ days in hospital the first year decreasing to $6.5 \pm 9$ days the fourth year. A significant higher admission rate was found for male infants, infants with $\mathrm{BW}<1.000$ grams, infants with broncopulmonary dysplasia (BPD), and infants treated for patent ductus arteriousus (PDA). Drugs were prescribed to $52.5 \%$ of infants with $1.5 \pm 1.8$ drugs/year. Infants with BPD and PDA and BW $<1000$ grams had significantly more drug prescriptions.

Conclusions Surviving VLBW infants have an increased need for health care resources several years after discharge. Emergency admissions and high admission rates in some infants might reflect suboptimal follow-up.

\section{LEVENE INDEX AT DIFFERENT GESTATIONAL AGES IN INFANTS $<32$ WEEKS}

doi:10.1136/archdischild-2012-302724.1269

${ }^{1} \mathrm{R}$ Shim, ${ }^{1} \mathrm{R}$ Gnanasakaran, ${ }^{2} \mathrm{M}$ Boyle, ${ }^{3} \mathrm{~S}$ Ryan, ${ }^{3} \mathrm{~A}$ Tarrant, ${ }^{4} \mathrm{~N}$ McCallion. ${ }^{1}$ Department of Paediatrics, RCSI; '2Department of Paediatrics, ' ${ }^{3}$ Dept of Radiolology, Rotunda Hospital; ${ }^{4}$ Department of Paediatrics, Rotunda Hospital/Royal College of Surgeons in Ireland, Dublin, Ireland

Background Levene index is used for the diagnosis of ventricular enlargement, including intraventricular haemorrahage and post haemorragic ventricular dilation. The original data dates from the 1980s and more recent studies are based on relatively small numbers of infants.

Aim To describe normal values for Levene Index at different gestations.

Method The serial cranial ultrasounds were reviewed of all preterm infants with gestation under 32 weeks admitted to Rotunda 